\title{
Alterações morfológicas foliares em abacaxizeiros cv. IAC "Gomo-de-mel" micropropagados e aclimatizados em diferentes condições de luminosidade
}

\author{
Katherine Derlene Batagin ${ }^{1}$, Cristina Vieira de Almeida ${ }^{2}$, Francisco André Ossamu Tanaka ${ }^{1}$ e \\ Marcílio de Almeida ${ }^{1,3}$
}

Recebido em 26/11/2007. Aceito em 25/04/2008

\begin{abstract}
RESUMO - (Alterações morfológicas foliares em abacaxizeiros cv. IAC “Gomo-de-mel” micropropagados e aclimatizados em diferentes condições de luminosidade). Plantas micropropagadas geralmente apresentam dificuldades de adaptação ao meio ex vitro, sendo muitas vezes submetidas a processos de rustificação para minimizar os impactos decorrentes da mudança de ambiente. Uma vez que a folha e seus anexos destacam-se como importantes indicativos das estratégias adaptativas das plantas a ambientes adversos, este trabalho teve por objetivo comparar a anatomia foliar de plantas de abacaxi cv. IAC "Gomo-de-mel" cultivadas in vitro com microplantas aclimatizadas em diferentes condições de luminosidade, sob telado com 50\% de sombreamento e em pleno sol para verificar a necessidade do processo de rustificação para este cultivar. Avaliações por meio de microscopia de luz e eletrônica de varredura da epiderme foliar, demonstraram aumento na densidade de escamas em ambas as superfícies das folhas, em microplantas dos ambientes ex vitro, principalmente em relação às que foram expostas diretamente ao sol. Observou-se ainda, aumento no espessamento da cutícula, na sinuosidade das células epidérmicas, e na distribuição e quantidade de fibras no mesofilo evidenciando a interferência das condições de luminosidade nas características morfológicas das microplantas. Essas alterações não prejudicaram o desenvolvimento das microplantas, indicando que não são necessárias etapas de rustificação para a aclimatização deste cultivar.
\end{abstract}

Palavras-chave: aclimatização, Ananas comosus, anexos epidérmicos, microplantas

\begin{abstract}
Morphological alterations in leave of micropropagated pineapple plants cv. IAC "Gomo-de-mel" acclimatizated in different conditions of luminosity). Microprapagated plants usually show difficulties to adapt to ex vitro conditions, and many times are submitted to the rustication process to aim the reduction of all the impacts resulting from the environmental changes. Once the leaf and its annexes are important indicators of adaptability strategies of the plants to adverse environmental conditions, the objective of this work was to compare the leaf anatomy of pineapple cv. IAC "Gomo-de-mel" in vitro cultivated plants with microplants acclimatized in different conditions of luminosity, under mesh, with $50 \%$ of shading and directly exposed to sunlight, to verify the needed of rustication process on this cultivar. Evaluations of the leaf epidermis using light and electronic scanning microscopy showed an increase on scale density in both leaves surfaces of the ex vitro microplants, mainly related to the ones directly exposed to sunlight. Subsequent observations showed an increase on cuticle thickness, on wavy contours of epidermal cells, and on the distribution and quantity of mesophyll fibers, evidencing the light conditions interference in morphological characteristics of these microplants. These alterations had not harmed microplant development, showing that are not need of rustication stages on the acclimatization process of this cultivar.
\end{abstract}

Key words: acclimatization, Ananas comosus, epidermal annexes, microplants

\section{Introdução}

A aplicação da técnica de cultura de tecidos é de extrema importância para o agronegócio bem como para as inovações biotecnológicas. O estabelecimento de um protocolo de microprogagação de espécies vegetais é dependente de uma gama de fatores bióticos e abióticos que afetam direta ou indiretamente a adaptação dos propágulos as condições ex vitro, uma vez que as microplantas se desenvolveram em condições heterotróficas. A transição de estádios fisiológicos das microplantas (heterotróficas para autotróficas) pode ocasionar perdas exorbitantes de indivíduos, inviabilizando o processo de micropropagação. Por essa razão, frequentemente as microplantas são submetidas a etapas de rustificação, que consistem na exposição gradativa dessas as condições externas, onde são controladas a luminosidade e a umidade relativa. As estratégias adaptativas dos propágulos podem acarretar diferenças significativas na morfologia interna e externa,

\footnotetext{
1 Universidade de São Paulo, Escola Superior de Agricultura "Luiz de Queiroz”, Departamento de Ciências Biológicas, Av. Pádua Dias 11, C. Postal 9, 13418-900 Piracicaba, SP, Brasil

2 In vitro Palm Consultoria Ltda, Rua Itajobi 421, 13432-000 Piracicaba, SP, Brasil

3 Autor para correspondência: malmeida@esalq.usp.br
} 
tanto do sistema aéreo como no sistema radicular, sendo essas adaptações mais expressivas no sistema aéreo, principalmente nas folhas (Ehrendorf 1973; Sutter \& Hutzell 1984).

Inúmeras são as espécies cultivadas por micropropagação e dentre elas a microcultura de abacaxis demonstra notável eficiência (Mathews \& Rangan 1974; Zepeda \& Sagawa 1981; Dewald et al. 1988; Guerra et al. 1999; Dalvesco et al. 2000; Almeida et al. 2002; Macedo et al. 2003).

O Instituto Agronômico de Campinas (IAC) vem desenvolvendo desde 1991, um programa de melhoramento genético de abacaxi, visando à resistência à fusariose e características agrícolas e organolépticas mais desejáveis, resultando na obtenção do cv. IAC "Gomo-de-mel", que se destaca por apresentar fatores desejáveis ao mercado, como o elevado teor de sólidos solúveis totais, acidez baixa a moderada, consistência tenra, suculência e coloração amarelo ouro atraente, que apresenta gomos destacáveis manualmente, o que justifica sua designação (Usberti Filho et al. 1999).

Ao que se refere à anatomia foliar dos abacaxizeiros, são descritas estruturas anatômicas típicas de bromeliáceas, como a presença de tricomas, ceras, estômatos presentes apenas na superfície abaxial, epiderme unisseriada revestida por cutícula, mesofilo constituído de hipoderme, presença de parênquima aqǘfero, com parênquima clorofiliano homogêneo, feixes vasculares colaterais fechados, cordões de fibras e canais de aeração (Py 1969).

Análises histológicas por meio de microscopia de luz e da densidade estomática do limbo foliar de abacaxi cv. Pérola cultivados in vitro e ex vitro em casa de vegetação, revelaram alterações ocorridas no processo de aclimatização das microplantas, evidenciando sua plasticidade fenotípica (Barboza et al. 2006).

Com base no trabalho dos autores supracitados quanto à plasticidade fenotípica do cv. Pérola, o presente trabalho realizou avaliações semelhantes em folhas de abacaxizeiro Ananas comosus (L.) Merrill cv. IAC "Gomo-de-mel". Sendo assim, o objetivo foi fornecer subsídios para a melhor compreensão das formas adaptativas deste cultivar micropropagado, averiguando também a necessidade de processos de rustificação na aclimatização dessa cultura, ao se comparar a anatomia foliar de microplantas mantidas in vitro com microplantas aclimatizadas sob diferentes condições de luminosidade (sob telado com 50\% de sombreamento e em pleno sol).

\section{Material e métodos}

O experimento foi desenvolvido no Laboratório de morfogênese e biologia reprodutiva de plantas e na casa de vegetação pertencente ao Departamento de Ciências Biológicas da Escola Superior de Agricultura "Luiz de Queiroz" (ESALQ/USP) com a espécie Ananas comosus (L.) Merrill cv. IAC “Gomo-de-mel”, cultivada in vitro a partir de gemas axilares inoculadas em meio de cultura Murashige \& Skoog (1962) acrescido de BAP (6-benzilaminopurina) e ANA (ácido naftalenoacético), 0,8 e $2,4 \mathrm{mg} . \mathrm{L}^{-1}$, respectivamente, e mantidas em sala de crescimento com temperatura e luminosidade controladas $\left(27 \pm 2{ }^{\circ} \mathrm{C}\right.$ e irradiância de $42 \mu \mathrm{mol} / \mathrm{s} / \mathrm{m}^{2}$, respectivamente) sob fotoperíodo de 16 horas.

As microplantas foram transferidas para condições ex vitro após oito meses de cultivo in vitro. Utilizou-se para o plantio vasos plásticos com $11 \mathrm{~cm}$ diâm. e $10 \mathrm{~cm}$ alt., contendo terra vegetal. As microplantas foram mantidas em dois ambientes: casa de vegetação, sob telado com $50 \%$ de sombreamento e em campo em pleno sol, no período de fevereiro a setembro/2006.

A avaliação dos limbos foliares por meio de microscopia eletrônica de varredura foi realizada no Núcleo de Apoio à Pesquisa em Microscopia Eletrônica Aplicada a Agricultura (NAP/MEPA - ESALQ/USP). Foram coletadas amostras do terço mediano da sétima folha das microplantas, a partir do ápice, as quais foram cortadas em pedaços com aproximadamente $5 \mathrm{~mm}$, onde parte destas amostras foram mantidas intactas e parte foi lavada, escovada e sobre sua superfície aderida uma fita adesiva, visando a retirada completa das escamas. Ambos os tipos de amostras foram posteriormente fixados em solução de Karnovsky (1965) modificado (glutaraldeído 2,5\%, formaldeído 2,5\% em tampão cacodilato de sódio $0,05 \mathrm{M}, \mathrm{pH} 7,2$ ), por 24 horas. Decorrido esse período as amostras foram pós fixadas em tetróxido de ósmio $\left(\mathrm{OsO}_{4}\right)$ e desidratadas em série crescente de acetona. A secagem, realizada ao ponto crítico (BALZERS CPD 030) teve como meio de desidratação, $\mathrm{o} \mathrm{CO}_{2}$ e, em seguida, foram metalizadas com ouro (metalizador MED 010 BALZERS), e examinadas em microscópio eletrônico de varredura ZEISS SEM 940.

O número de estômatos e escamas foi determinado pelo método de impressão epidérmica (Segatto et al. 2004), utilizando éster de cianoacrilato (LOCTITE ${ }^{\circledR}$ ). As lâminas histológicas foram analisadas em microscópio de luz equipado com ocular quadriculada com área foliar de $0,78 \mathrm{~mm}^{2}$. Para tanto, utilizou-se a região mediana das quartas, sextas e oitavas folhas, a partir do ápice, selecionadas como forma de padronização de análises, devido a filotaxia 5/13 característica dos abacaxizeiros.

Para a confecção de lâminas permanentes, foram utilizadas amostras do terço mediano das sétimas folhas dos abacaxizeiros, a partir do ápice. Foram analisadas cinco lâminas histológicas por folha, de cinco plantas 
acondicionadas em cada um dos ambientes (in vitro e ex vitro), totalizando 25 lâminas para cada tratamento. Para tanto, o material vegetal foi fixado em solução de Karnovsky (1965), por um período de três dias, seguido pela desidratação do material em série crescente de etanol, permanecendo em cada uma delas por 10 minutos, e por fim realizou-se a infiltração em resina de hidroxietilmetacrilato (LEICA-HISTORESIN), de acordo com as recomendações do fabricante.

$\mathrm{O}$ material vegetal emblocado foi cortado em micrótomo rotativo (E.LEITZ LAR) em secções transversais com $5 \mu \mathrm{m}$ de espes. As secções foram coradas com azul de toluidina a $0,05 \%$ (v/v) em tampão fosfato e ácido cítrico (Sakai 1973) e montados em lâminas histológicas com a resina sintética $\left(\right.$ ENTELLAN $\left.^{\circledR}\right)$.

As análises das epidermes em vista frontal foram realizadas no terço mediano das quintas folhas dos abacaxizeiros, a partir do ápice, onde foram confeccionadas lâminas semi-permanentes, utilizandose a dissociação do mesofilo por solução de Jeffrey (Johansen 1940). As lâminas foram coradas em safranina e montadas com gelatina glicerinada (Kaiser 1880).

As lâminas histológicas foram analisadas e as imagens obtidas em microscópio de luz (ZEISS/ JENAMED, 2) acoplado a um sistema de captura de imagens com as respectivas escalas na mesma proporção.

\section{Resultados e discussão}

O abacaxi cv. IAC "Gomo-de-mel" quando desenvolvido in vitro apresenta plantas com ótimo padrão e qualidade (Fig. 1), resultado também observado em outros cultivares da mesma espécie (Guerra et al. 1999; Dalvesco et al. 2000; Teixeira et al. 2001; Almeida et al.
2002; Macedo et al. 2003; Moreira et al. 2003; Barboza et al. 2006).

Quando transferidas para condições ex vitro, as microplantas do cv. IAC "Gomo-de-mel" apresentam $100 \%$ de sobrevivência, tanto sob telado com $50 \%$ de sombreamento (Fig. 2) quanto na condição em pleno sol (Fig. 3), constatando que a mudança de metabolismo heterotrófico para autotrófico não é um fator limitante para a aclimatização deste cultivar. Entretanto, alterações estruturais podem ser verificadas nas plantas in vitro, quando transferidas as condições ex vitro.

Por meio de microscopia eletrônica de varredura é evidenciada a presença de tricomas glandulares multicelulares e unisseriados (Fig. 4) e tricomas não glandulares escamiformes, achatados e multicelulares (Fig. 5) na superfície epidérmica das plantas cultivadas in vitro Barboza et al. (2006), apenas descrevem a presença de tricomas glandulares no cv. Pérola micropropagado, e atribuem a esses tricomas, uma forma de adaptação morfológica, que atua na restrição da perda de água pelas folhas, por meio da regulação da temperatura pela reflexão da luz, além de poder secretar substâncias que protegem as folhas contra parasitas e predadores. Nas microplantas do cv. IAC "Gomo-demel" acondicionadas ex vitro não se verifica a presença de tricomas glandulares devido à elevada concentração de tricomas escamiformes (escamas) em ambas as superfícies foliares, recobrindo os estômatos (Fig. 6). Segundo Ehleringer \& Mooney (1978) a presença das escamas demonstram uma adaptação morfológica que favorece a manutenção da assimilação de $\mathrm{CO}_{2} \mathrm{e}$ da transpiração, uma vez que diminuem o contato direto da superfície estomática com o ambiente.

De acordo com Tomlison (1969); Fahn (1986); Sousa \& Neves (1996) e Larcher (2000), as escamas desempenham funções importantes no limbo foliar como
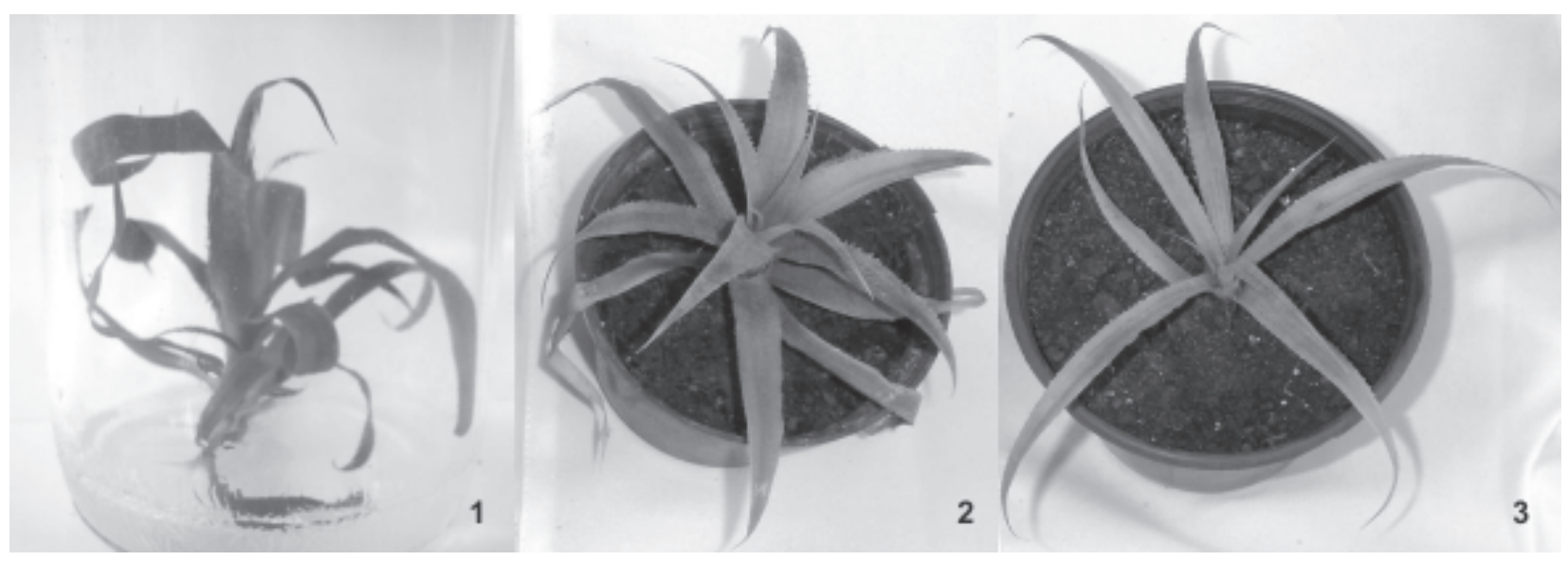

Figuras 1-3. Microplantas de abacaxi (Ananas comosus (L.) Merrill cv. IAC “Gomo-de-mel”) acondicionadas: in vitro (1), sob telado com 50\% de sombreamento (2) e em pleno sol (3). 
proteção mecânica e proteção contra a perda excessiva de água, mantendo uma atmosfera saturada de vapor em torno da folha, resultando na redução da transpiração. Os tricomas glandulares por sua vez, segundo Dimock \& Kennedy (1983) podem sintetizar substâncias especializadas, como alguns metabólitos secundários, em particular os de características voláteis, e em algumas plantas como tomateiros, apresentam não somente a função secretora de exsudatos químicos, mas também constituem a base mecânica da resistência a diferentes insetos.

Observa-se que as plantas in vitro do cv. IAC "Gomo-de-mel" apresentam na região mediana das folhas em média 3 escamas $\mathrm{mm}^{-2}$ na superfície adaxial (Fig. 7) e 6 escamas $\mathrm{mm}^{-2}$ na abaxial (Fig. 10). No caso das microplantas mantidas sob telado com $50 \%$ de sombreamento, observa-se em média 7 e 11 escamas $\mathrm{mm}^{-2}$ na superfície adaxial e abaxial, respectivamente (Fig. 8, 11),

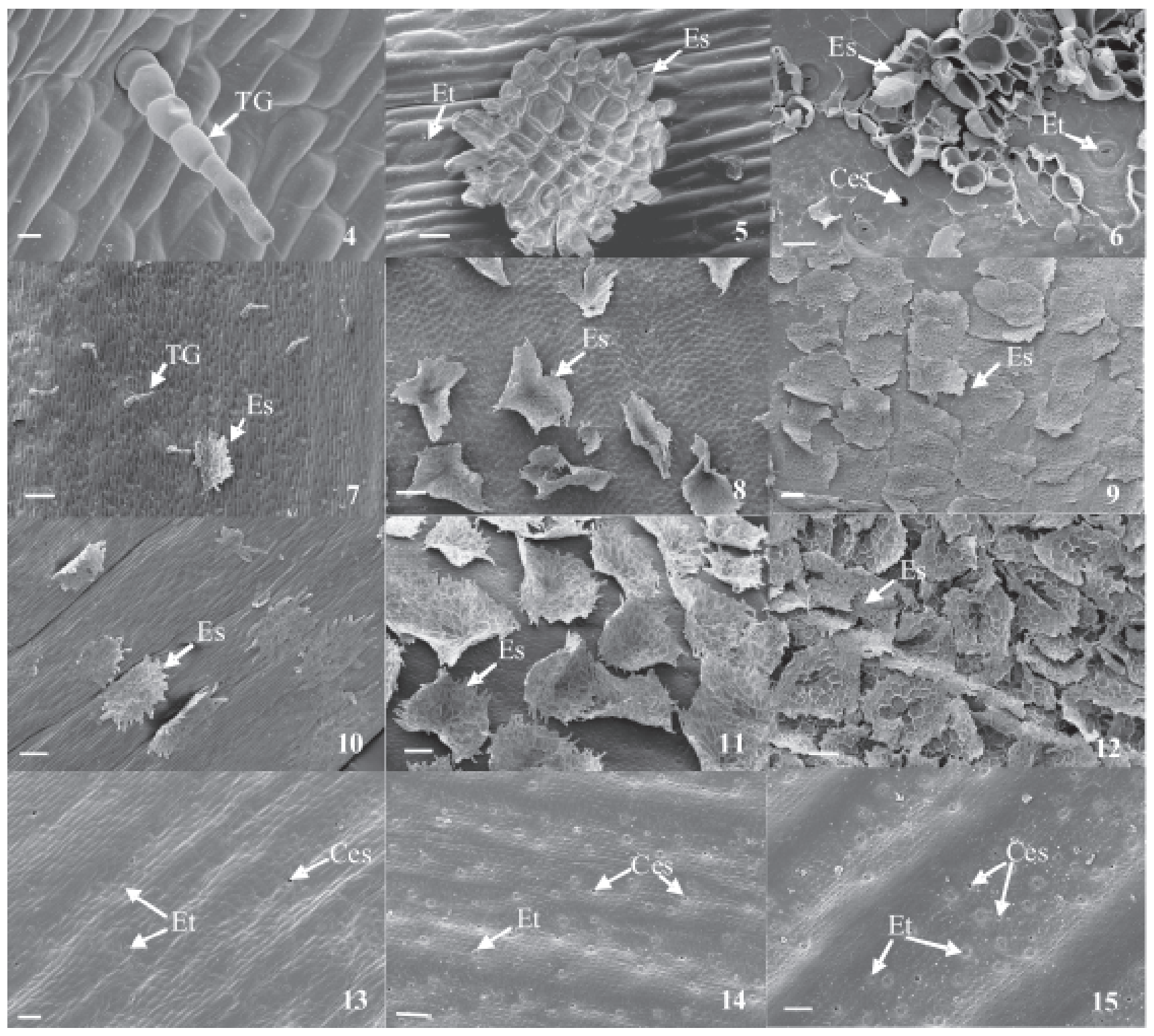

Figuras 4-15. Fotomicrografia eletrônica de varredura das epidermes foliares de microplantas de abacaxi (Ananas comosus (L.) Merrill cv. IAC "Gomo-de-mel"). 4. Tricoma glandular na superfície adaxial de microplanta in vitro. 5. Tricoma não glandular (escama) na superfície abaxial da microplanta in vitro. 6. Presença de estômatos sob as escamas na superfície abaxial de microplanta acondicionada em pleno sol. 7-9. Superfícies adaxiais de microplantas acondicionadas: in vitro (7), sob telado com 50\% de sombreamento (8) e em pleno sol (9). 10-12. Superfícies abaxiais intactas de microplantas acondicionadas: in vitro (10), sob telado com 50\% de sombreamento (11) e em pleno sol (12). 13-15. Superfícies abaxiais com remoção das escamas de microplantas acondicionadas: in vitro (13), sob telado com 50\% de sombreamento (14) e em pleno sol (15). Ces-cicatriz de escama; Es-escama; Et-estômato; TG-tricoma glandular. Barras = $10 \mu \mathrm{m}(4) ; 20 \mu \mathrm{m}(5) ; 30 \mu \mathrm{m}(6) ; 60 \mu \mathrm{m}(13$ e 15) e $100 \mu \mathrm{m}(7-12$ e 14$)$. 
ao passo que as microplantas mantidas em pleno sol a epiderme adaxial apresenta 12 escamas $\mathrm{mm}^{-2}$ (Fig. 9), enquanto a abaxial 22 escamas $\mathrm{mm}^{-2}$ (Fig. 12). Pode-se inferir que, a concentração de escamas difere de acordo com a intensidade luminosa, sendo maior nas microplantas em pleno sol.

Com a remoção das escamas sobre a superfície foliar, observa-se em vista frontal, que as células epidérmicas das microplantas do cv. IAC "Gomo-de-mel" estão organizadas em fileiras paralelas ao longo do eixo da folha (Fig. 13-15), constituída por células longas de forma retangular justapostas, alternando-se às vezes, em células curtas que variam em comprimento e largura. Em corte transversal, apresentam-se unisseriadas e revestidas por cutícula lisa e levemente ondulada. O padrão de espessamento da parede periclinal externa das células epidérmicas difere em relação à condição de luminosidade, sendo que nas microplantas cultivadas in vitro apresentam espessamento médio de $7 \mu \mathrm{m}$ na epiderme adaxial e $2 \mu \mathrm{m}$ na epiderme abaxial (Fig. 16, 19). No entanto, nas plantas acondicionadas ex vitro apresentam um aumento considerável, todavia, tanto as microplantas mantidas sob telado com $50 \%$ de sombreamento (Fig. 17, 20) quanto as mantidas em pleno sol (Fig. 18, 21) apresentam aproximadamente $11 \mu \mathrm{m}$ espes. na parede epidérmica adaxial e $7 \mu \mathrm{m}$ na abaxial. Esses resultados obedecem ao padrão de espessamento da parede determinado pelo grau de exposição ao sol, semelhantes aos resultados obtidos por Withner et al. (1974) em orquídeas.

Os estômatos são raros ou mesmo ausentes na superfície adaxial e abundantes na superfície abaxial das folhas. Tanto as plantas in vitro quanto as ex vitro cultivadas sob telado com $50 \%$ de sombreamento apresentam em média 33 estômatos $\mathrm{mm}^{-2}$ ao passo que as mantidas em pleno sol apresentam em média $49 \mathrm{~mm}^{-2}$. Essas densidades são consideradas baixas em comparação aos outros cultivares, como por exemplo, o cv. Pérola que apresenta em média 54 estômatos $\mathrm{mm}^{-2}$ in vitro, 62 estômatos $\mathrm{mm}^{-2} \mathrm{em}$ casa de vegetação (Barboza et al. 2006) e 70 a 85 estômatos $\mathrm{mm}^{-2} \mathrm{em}$ condição de campo (Py 1969). Entretanto, mesmo com o baixo número de estômatos apresentado no cv. IAC "Gomo-de-mel" observa-se uma tendência à diminuição da densidade estomática tanto nas plantas in vitro quanto nas mantidas sob telado com $50 \%$ de sombreamento em comparação às mantidas em pleno sol para esse cultivar. Provavelmente isto se deve, no caso das plantas in vitro à sua condição heterotrófica bem como a condição de umidade e luz controlada às quais estão submetidas. Além disso, considera-se que a variação na densidade estomática presente entre as microplantas acondicionadas ex vitro está diretamente relacionada à intensidade luminosa.
Nas folhas de plantas in vitro do cv. IAC "Gomode-mel" observa-se que tanto as escamas quanto os estômatos encontram-se dispersos sobre a superfície foliar, e essa superfície apresenta-se plana (Fig. 13). À medida que a microplanta é transferida da condição in vitro, para as condições ex vitro sob telado com $50 \%$ de sombreamento e em pleno sol, a superfície foliar torna-se gradativamente mais sinuosa (Fig. 14-15). Os estômatos e escamas encontram-se em maior concentração nos sulcos longitudinais decorrentes da sinuosidade da superfície foliar, tanto nas microplantas mantidas sob telado com $50 \%$ de sombreamento quanto nas expostas em pleno sol (Fig. 14-15). Essa característica é muito comum em plantas submetidas a ambientes secos como observado por Metcalfe (1960) e Lyshede (1982).

Os estômatos em todas as microplantas avaliadas ocorrem nos mesmos níveis das demais células epidérmicas ou em posição ligeiramente elevada, não ocorrendo em cavidades ou criptas, seguem o padrão tetracítico (Fig. 22), com células guardas riniformes e câmaras subestomáticas típicas, bem definidas (Fig. 23), característica comum a muitas espécies da família Bromeliaceae descritas por diversos autores (Aoyama \& Sajo 2003; Scatena \& Segecin 2005; Souza et al. 2005; Barboza et al. 2006).

Todas as microplantas avaliadas apresentam uma hipoderme (Fig. 24) junto a epiderme da face adaxial, característica de muitos representantes da família Bromeliaceae. Este tecido, segundo Madison (1977), armazena água exercendo importante papel na economia de calor, especialmente em plantas com metabolismo CAM, evitando o colapso das células pelo murchamento.

Adjacente à hipoderme, observa-se em todas as folhas das microplantas do cv. IAC "Gomo-de-mel", a ocorrência do parênquima aquífero, o qual varia de duas a quatro camadas celulares nas diferentes condições ambientais (Fig. 24-26). Segundo Loeschen et al. (1993), esta característica é importante em plantas com metabolismo CAM, contribuindo para a adaptação desta em ambientes sujeitos a desidratação. Esses resultados corroboram as afirmações de Barboza et al. (2006) no cv. Pérola, onde os autores salientam que tanto a hipoderme quanto o parênquima aqüífero podem não exercer funções bem definidas em plantas in vitro, devido à condição heterotrófica e controlada a qual está submetida, encontrando-se em um ambiente onde há disponibilidade de luz, água e nutrientes. Entretanto, os autores afirmam que esses tecidos podem assumir grande importância no momento da aclimatização, impedindo a desidratação das microplantas nos primeiros dias após o plantio, podendo assim a presença destes tecidos (hipoderme e parênquima aqüífero), em plantas in vitro estarem correlacionados ao alto índice de sobrevivência 
dos abacaxizeiros quando transferidos para as condições ex vitro.

No cv. IAC “Gomo-de-mel” observa-se diferenças marcantes entre o parênquima aqüífero e o parênquima clorofiliano, sendo que na região central do limbo foliar o parênquima aqüífero ocupa até $50 \%$ do mesofilo (Fig. 25), caracterizando a simetria dorsiventral em todas as folhas analisadas, fato este não verificado em direção às margens, onde ocorre a predominância do parênquima clorofiliano, o qual ocupa $100 \%$ do mesofilo (Fig. 18).

Em todas as microplantas as nervuras das folhas apresentam feixes vasculares colaterais fechados com pequeno, médio e grande portes, localizados próximos à superfície abaxial, juntamente ao parênquima clorofiliano (Fig. 17-18, 25, 27).

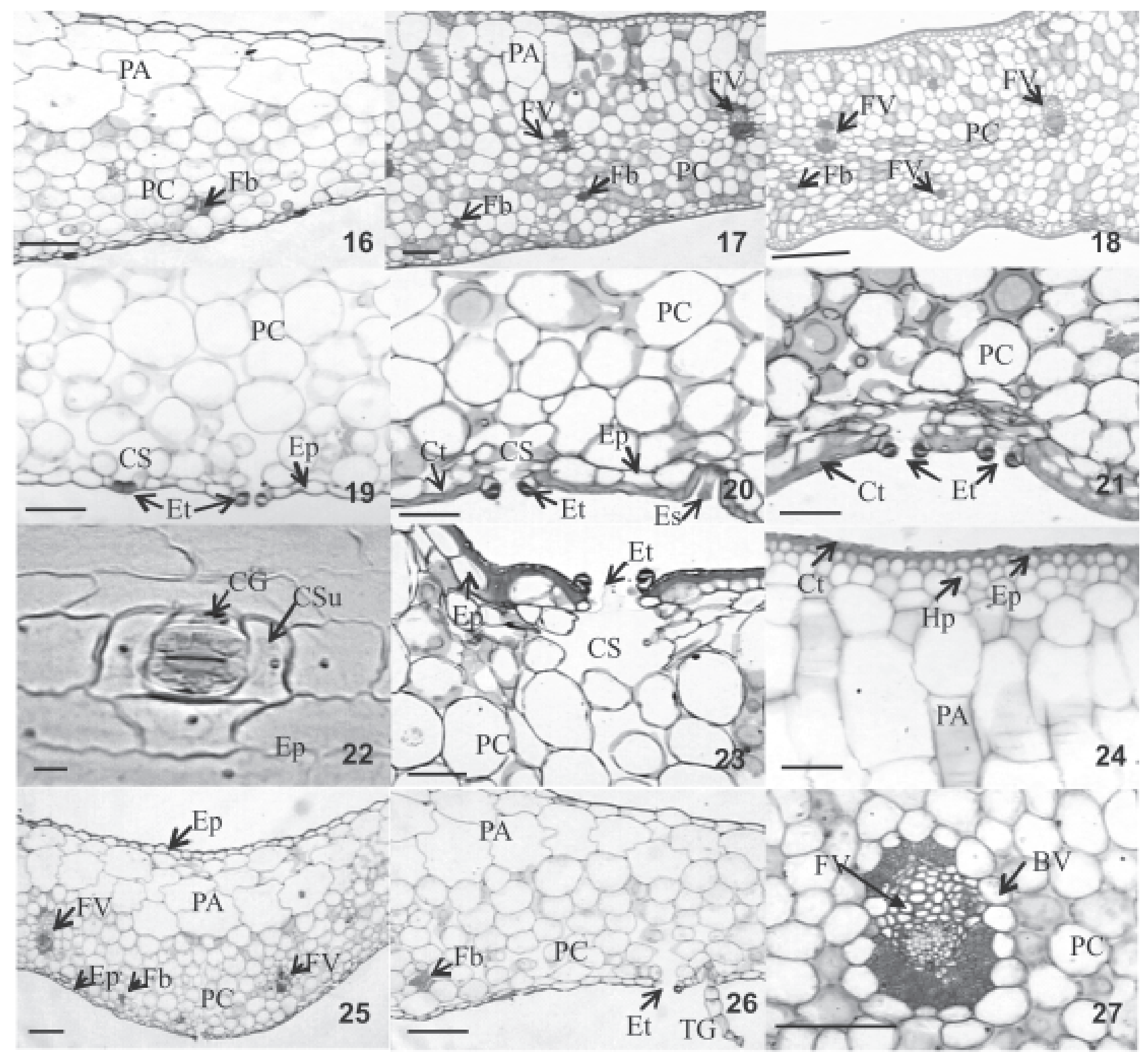

Figuras 16-27. Secções histológicos de folhas de microplantas de abacaxi (Ananas comosus (L.) Merril cv. IAC "Gomo-de-Mel”). 16-18. Corte transversal da região do bordo foliar ressaltando as epidermes adaxial e abaxial das microplantas acondicionadas: in vitro (16), sob telado com $50 \%$ de sombreamento (17) e em pleno sol (18). 19-21. Secção transversal evidenciando as superfícies abaxiais das microplantas acondicionadas: in vitro (19), sob telado com $50 \%$ de sombreamento (20) e em pleno sol (21). 22-23. Estômato tetracítico: secção paradérmico (22) e secção transversal (23). 24-26. Secções transversais evidenciando: a região da superfície adaxial (24); região central do limbo foliar (25) e região do bordo foliar (26). 27. Detalhe feixe vascular colateral. BV - Bainha vascular; Ct - Cutícula; CG - Célula-guarda; CS - Câmara subestomática; CSu - célula subsidiária; Ep - Epiderme; Es-escama; Et - Estômato; Fb - Fibras; FV - Feixe vascular; Hp - Hipoderme; PC - Parênquima clorofiliano; PA - Parênquima aquífero; TG - Tricoma glandular. Barras $=10 \mu \mathrm{m}(22)$; $50 \mu \mathrm{m}(19-21$ e 23$)$ e $100 \mu \mathrm{m}(16-18$ e $24-27)$. 
Grupos de fibras de esclerênquima típicos de abacaxi e outras espécies da família Bromeliaceae, são observados associados aos feixes vasculares e dispersos por todo mesofilo, (Cutter 1986; Krauss 1948). A concentração de fibras aparentemente é menor em plantas in vitro quando comparadas com as mantidas ex vitro, mostrando-se mais concentradas nas microplantas mantidas em pleno sol. Este resultado permite inferir que dependendo do grau de aclimatização, a presença de fibras no mesofilo pode estar associada à exposição das plantas a diferentes intensidades luminosas que poderá conferir a essas plantas, suporte mecânico ou mesmo proteção dos tecidos vasculares ao ataque de insetos (Pyykkö 1966; Mauseth 1988).

Outra estrutura observada, característica de plantas com metabolismo CAM, são as células parenquimáticas da bainha do feixe vascular (Fig. 27), responsáveis pela assimilação fotossintética do carbono (Dengler et al. 1985), as quais circundam parcialmente o feixe, sendo interrompidas por células esclerenquimáticas (fibras) próximas ao floema.

Todas as estruturas e alterações supracitadas são comuns também ao cv. Pérola, entretanto em todas as plantas do cv. IAC "Gomo-de-mel", nas três condições ambientais estudadas, não foi observada a ocorrência de cavidades aeríferas, estrutura freqüentemente encontrada em representantes de Bromeliaceae, inclusive nas espécies do gênero Ananas (Tomlinson 1969; Sousa \& Neves 1996; Souza et al. 2005; Barboza et al. 2006), devendo esta ausência ser uma característica desse novo cultivar, o que pode contribuir para sua caracterização taxonômica.

Conclui-se que as alterações morfológicas verificadas nas folhas das microplantas do abacaxizeiro cv. IAC "Gomo-de- mel" são resultantes da interferência da luz nas diferentes condições de aclimatização. As alterações não afetaram o desenvolvimento das microplantas em ambas as condições de luminosidade, não sendo necessário, portanto, o processo de rustificação para este cultivar.

\section{Agradecimentos}

À Sra. Cássia Regina Fernandes Figueiredo, do Laboratório de Morfogênese e Biologia Reprodutiva de Plantas do Departamento de Ciências Biológicas, ESALQ-USP, Piracicaba, SP, pelo auxílio na preparação das lâminas histológicas; ao Prof. Dr. Elliot Watanabe Kitajima, do NAP/MEPA-ESALQ-USP, Piracicaba, SP, pelo uso dos equipamentos para análise em Microscopia Eletrônica de Varredura.

\section{Referências bibliográficas}

Almeida, O.A.; Souza, L.F.S.; Reinhardt, D.H. \& Caldas, R.C. 2002. Influência da irrigação no ciclo do abacaxizeiro cv. Pérola em área de tabuleiro costeiro da Bahia. Revista Brasileira de Fruticultura 24: 431-435.

Aoyama, E.M. \& Sajo, M.G. 2003. Estrutura foliar de Aechmea Ruiz \& Pav. subgênero Lamprococcus (Beer) Baker e espécies relacionadas. Revista Brasileira de Botânica 26: 461-473.

Barboza, S.B.S.C.B.; Graciano-Ribeiro, D.; Teixeira, J.B.; Portes, T.A. \& Souza, L.A.C. 2006. Anatomia foliar de plantas micropropagadas de abacaxi. Pesquisa agropecuária brasileira 41: 185-194.

Cutter, E.G. 1978. Plant anatomy - Part I: cells and tissues. $2^{\text {nd }}$ ed. London, Edward Arnold.

Dalvesco, L.L.; Pescador, R.; Beló, A.; Feuser, S.; Oliveira, E.N.; Brancher, A.; Zaffari, G.R.; Nodari, R.O. \& Guerra, M.P. 2000. Qualidade genotípica de mudas e performance a campo de plantas micropropagadas de abacaxizeiro. Revista Brasileira de Fruticultura 22: 80-85.

Dengler, N.G.; Dengler, R.E. \& Hattersley, P.W. 1985. Differing ontogenetic origins of PCR (Kranz) sheaths in leaf blades of C4 grasses (POACEAE). American Journal of Botany 72: 284-302.

Dewald, M.G.; Moore, G.A. \& Sherman, W.B. 1988. Identification of pineapple cultivars by isozyme. Journal of American Society of Horticultural Science 113: 935-938,

Dimock M.B. \& Kennedy G.G. 1983. The role of glandular trichomes in the resistance of Lycopersicon hirsutum $\mathrm{f}$. glabratum to Heliothis zea. Entomologia Experimentalis et Applicata 33: 263-268.

Ehleringer, J.R. \& Mooney, H.A. 1978. Leaf hairs: effect on physiological activity and adaptative value to a desert shrub. Oecologia 37: 183-200.

Ehrendorfer, F. 1973. Adaptive significance of major taxonomic characters and morphological trends in angiosperms. Pp. 317-327. In: V.H. Heywood (ed.). Taxonomy and ecology. London, Academic Press.

Fahn, A. 1986. Structural and functional properties of trichomes of xeromorphic leaves. Annals of Botany 57: 631-637.

Guerra, M.P.; Vesco, L.L.D.; Pescador, R.; Schuelter R. \& Nodari, R.O. 1999. Estabelecimento de um protocolo regenerativo para a micropropagação do abacaxizeiro (Ananas comosus (L.) Merr.). Pesquisa Agropecuária Brasileira 34: 1557-1563.

Johansen, D.A. 1940. Plant microtechnique. New York, McGraw Hill.

Kaiser, E. 1880. Verfahren zur Herstellung einer tadellosen Glycerin-Gelatine. Botanisch Zentralb 180: 25-26.

Karnovsky, M.J. 1965 A formaldehyde-glutaraldehyde fixative of high osmolality for use in eletron microscopy. Journal of Cellular Biology 27: 137-138.

Krauss, B.H. 1949. Anatomy of the vegetative organs of the pineapple, Ananas comosus (L.) Merr. II. The leaf. Botanical Gazette 110: 333-404.

Larcher, W. 2000. Ecofisiologia vegetal. São Carlos, Rima. 
Loeschen, V.S.; Martin, C.E.; Smith, M. \& Eder, S.L. 1993. Leaf anatomy and $\mathrm{CO}_{2}$ recycling during crassulacean acid metabolism in twelve epiphytic epecies of Tillandsia (Bromeliaceae). International Journal of Plant Sciences 154: 100-106.

Lyshede, O.B. 1982. Structure of the outer epidermal wall in xerophytes. Pp. 87-98. In: The plant cuticle. D.F. Cutler, K.L. Alvin \& C.E. Price (eds.). London, Academic Press.

Macedo, C.E.C.; Silva, M.G.; Nobrega, F.S.; Martins, C.P.; Barroso, P.A.V. \& Alloufa, M.A.I. 2003. Concentrações de ANA e BAP na micropropagação de abacaxizeiro L. Merril (Ananas comosus) e no cultivo hidropônico das plântulas obtidas in vitro. Revista Brasileira de Fruticultura 25: 501-504.

Madison, M. 1977. Vascular epiphytes: their systematic occurrence and salient features. Selbyana 2: 1-13.

Mathews, V.H. \& Rangan, T.S. 1974. Multiple plantlet in lateral bud leaf explant in vitro culture of pineapple. Scientia Horticulturae 14: 227-234.

Mauseth, J.D. 1988. Plant anatomy. The Benjamin/Cummings Publishing Company, Menlo Park.

Metcalfe, C.R. 1960. Anatomy of the Monocotyledons. Oxford, Clarendon Press.

Moreira, M.A.; Pasqual, M.; Carvalho, J.G. \& Fráguas, C.B. 2003. Estiolamento na micropropagação do abacaxizeiro cv. Pérola. Ciências agrotécnica 27: 1002-1006.

Murashige, T. \& Skoog, F. 1962. A revised medium for rapid growth and bioassays with tobacco tissue culture. Physiologia Plantarum 15: 473-497.

Py, C. 1969. La Piña Tropical. Barcelona, Editorial Blume.

Pyykkö, M. 1966. The leaf anatomy of east Patagonian xeromorphic plants. American Journal of Botany 68: 6471.

Sakai, W.S. 1973. Simple method for differential staining of paraffin embedded plant material using toluidine blue O. Stain Technology 48: 247-249.
Scatena, V.L. \& Segecin, S. 2005. Anatomia foliar de Tillandsia L. (Bromeliaceae) dos Campos Gerais, Paraná, Brasil. Revista Brasileira de Botânica 28: 635-649.

Segatto, F.B.; Bisognin, D.A.; Benedetti, M.; Costa, L.C.; Rampelotto, M.V. \& Nicoloso, F.T. 2004. Técnica para o estudo da anatomia da epiderme foliar de batata. Ciene Rural 34: 1597-1601.

Sousa, R.C.O.S. \& Neves, L.J. 1996. Leaf anatomy of four Tillandsia species. Bromelia 3: 28-39.

Souza, G.M.; Estelita, M.E.M. \& Wanderley, M.G.L. 2005. Anatomia foliar de espécies brasileiras de Aechmea subg. Chevaliera (Gaudich. ex Beer) Baker, BromelioideaeBromeliaceae. Revista Brasileira de Botânica 28: 603-613.

Sutter, E.G. \& Hutzell, M. 1984. Use of humidity tents and antitranspirants in the acclimatization to tissue-cultured plants to the greenhouse. Scientia Horticulturae 23: 303-312.

Teixeira, J.B.; Cruz, A.R.R.; Ferreira, F.R. \& Cabral, J.R. 2001. Biotecnologia aplicada à produção de mudas: produção de mudas micropropagadas de abacaxi. Biotecnologia. Ciência e Desenvolvimento 3: 42-47.

Tomlinson, P.B. 1969. Commelinales-Zingiberales. Pp. 295-421. In: C.R. Metcalfe (ed.). Anatomy of the monocotyledons. Oxford, Clarendon Press.

Usberti Filho, J.A.; Siqueira, W.J.; Spironello, A.; Tanaka, M.A.S.; Sigrist, J.M.M.; Martins, A.L.M.; Bortoletto, N.; Tsuhako A.T. \& Gushiken, A. 1999. IAC Gomo-de-mel. Campinas, Instituto Agronômico de Campinas (Folder).

Withner, C.L.; Nelson, P.K. \& Wejksnora, P.J. 1974. The anatomy of orchids. Pp. 267-334. In: C.L. Withner (ed.). The Orchids: scientific studies. New York, John Wiley.

Zepeda, C. \& Sagawa, Y. 1981. In vitro propagation of pineapple. Hort Science 16: 1-495.

Versão eletrônica do artigo em www.scielo.br/abb e http://www.botanica.org.br/acta/ojs 